\title{
EDUCAÇÃO SEXUAL NA MODALIDADE EAD: UM ESTUDO EXPLORATÓRIO
}

\author{
Sebastião Souza Lemes ${ }^{1}$ \\ Ana Cláudia Bortolozzi Maia ${ }^{2}$ \\ Verônica Lima dos Reis-Yamauti ${ }^{3}$
}

\begin{abstract}
A Educação a Distância (EaD) tornou-se uma possibilidade de formação ou educação continuada no Brasil, especialmente quando se trata de temas pouco abordados nos cursos de graduação. Esta pesquisa qualitativa-exploratória teve por objetivo levantar as propostas de cursos de formação em educação sexual, na modalidade $\mathrm{EaD}$ no Brasil. Realizou-se uma busca no site da Universidade Aberta do Brasil (UaB) e no site de busca livre - Google, a partir de critérios de seleção: ser nacional, estar vinculado à educação formal e ter como público alvo profissionais da educação. Os resultados evidenciaram 49 cursos, sendo 13 particulares e 36 gratuitos e públicos. Dos 13 particulares: 7 referem-se a cursos de curta duração com até 60 horas; 3 entre 10h/40h a 280h/300h; 2 têm nível de pós-graduação lato sensu com $360 \mathrm{~h} / 420 \mathrm{~h}$ e um, carga horária inespecífica. Os 36 cursos gratuitos são conveniados às propostas governamentais e direcionados à formação de educadores, sendo: 27 alocados em universidades federais e 9 em estaduais; 26 apresentam nível de aperfeiçoamento, 6 de extensão e 4 de especialização. Os cursos públicos em geral priorizam a educação sexual na escola; já os particulares abordam também questões de saúde. Conclui-se que há mais cursos públicos que particulares e, em alguns, reproduz-se a sexualidade relacionada à sexologia e não à educação. Neste sentido, seria importante investir na elaboração de cursos que abordem amplamente essa temática e objetivem a formação continuada de professores para atuar em práticas educativas nos contextos das escolas.
\end{abstract}

Palavras-chaves: Educação a Distância; Educação Sexual Formação de professores.

\section{Introdução}

A Educação a Distância (EaD) no Brasil, tem bases estabelecidas pela Lei de Diretrizes e Bases da Educação Nacional (Lei nº 9.394/1996), porém, tornou-se uma possibilidade de formação ou educação continuada a partir do Decreto $n^{\circ} 5.622 / 2005$, posteriormente ratificado por outros Decretos (5.773/2006, 6.303/2007). Trata-se de "um

\footnotetext{
${ }^{1}$ Universidade Estadual Paulista "Júlio de Mesquita Filho"- UNESP. - Faculdade Ciências e Letras Araraquara-SP. Programa de Pós-Graduação em Educação Escolar. E-mail: ss.lemes2@gmail.com

${ }^{2}$ Idem. E-mail: aclaudia@fc.unesp.br

${ }^{3}$ Idem. Email: veronica.reis@nepps.com.br
} 
conjunto de ações de ensino e aprendizagem que são desenvolvidas através de meios telemáticos como a Internet, a videoconferência e a teleconferência" (Barros, 2008, p.6). Caracteriza-se como tecnologia bidirecional, em que os alunos e professores estão física ou temporalmente separados (Aretio, 1987; Ministério da Educação e Cultura - MEC, 2014).

Rodrigues e Capellini (2012) analisaram a formação continuada em Educação Inclusiva na modalidade $\mathrm{EaD}$, em uma amostra de 182 professores cursistas e destacam como positivo a possibilidade de atendimento a um grande número de alunos, em diferentes áreas geográficas. Barros e Reis (2009) reforçam a possibilidade inovar a estrutura de cursos, criando métodos de ensino e trabalhos colaborativos que contribuem para o desenvolvimento de competências diversas.

Maia, Reis-Yamauti, Schiavo, Capellini e Valle (2014) estudaram os relatos de 451 professores da rede pública de ensino que opinaram sobre a sexualidade do aluno com Deficiência Intelectual em um curso na modalidade $\mathrm{EaD}$, destacando que essas propostas de formação continuada para educadores deveria abranger a educação sexual.

Para Mostafa (2009), o tema sexualidade foi considerado o mais difícil de ser trabalhado na formação docente, pois os professores cursistas demostravam desinformação e discutiam de forma genérica sobre preconceitos e estereótipos. Uma possível razão para isso são os valores pessoais dos professores, assim como o receio de que a família discorde da educação sexual ser ministrada na escola (Maia et al., 2014).

No Brasil, os Parâmetros Curriculares Nacionais - PCN (1997) discorre sobre a importância de incluir a educação sexual ${ }^{4}$ como tema transversal nos currículos, explicando qual o papel do educador e da escola na atuação educacional. Além disso, deixa claro que objetiva "promover reflexões e discussões de técnicos, professores, equipes pedagógicas, bem como de pais e responsáveis, com a finalidade de sistematizar a ação pedagógica da escola no trato de questões da sexualidade" (PCN, 1997, p.287).

Visando sistematizar ações para alcançar este objetivo, o MEC por meio da Secretaria de Educação Continuada, Alfabetização e Diversidade (SECAD) fez uma parceria com a Universidade Aberta do Brasil $(\mathrm{UaB})^{5}$, integrando universidades públicas que oferecem cursos de nível superior priorizando como público alvo professores e outros

\footnotetext{
${ }^{4}$ Nos Parâmetros Curriculares Nacionais, o termo utilizado é orientação sexual, todavia, aqui é apresentado como educação sexual, por melhor adequar-se ao conceito atualmente consagrado.

${ }^{5}$ Sistema instituído pelo Decreto 5.800/2006.
} 
profissionais que atuam na educação básica - servidores dos estados, municípios ou Distrito Federal.

Ressalta-se que a formação continuada do professor em educação sexual, torna-se ainda mais relevante, quando se constata que na graduação, em muitos casos, a grade curricular não contempla o conteúdo, o que gera uma prática pedagógica baseada na aprendizagem informal obtida pelo professor, seja pela família, religião, amigos e/ou mídia (Benites, 2006; Figueiró, 2001).

Considerando o exposto, esta pesquisa teve por objetivo levantar as propostas de cursos de formação em educação sexual, na modalidade EaD no Brasil.

\section{Método}

A coleta de dados ocorreu por meio da Internet (navegador Internet Explorer). A busca foi realizada nos sites: Universidade Aberta do Brasil (UaB) http://www.uab.capes.gov.br/; Google (site de busca livre) - https://www.google.com.br/, considerando os critérios de inclusão: (a) Ser nacional; (b) Estar vinculado à educação formal e (c) Ter como público alvo profissionais da educação. E os critérios de exclusão: (a) cursos de orientação ao público jovem sobre temas específicos (métodos contraceptivos, sedução, etc).

Para a coleta no site da UaB, a busca foi realizada em "cursos ofertados", utilizando-se inicialmente os termos "educação sexual" e "sexualidade". Para a busca no google as seguintes palavras-chaves foram cruzadas: "educação sexual", "EaD” e "Curso", sendo realizadas diferentes combinações entre os termos.

\section{Resultados}

Foram encontrados 49 cursos, sendo 36 gratuitos e públicos e 13 particulares.

Os 36 cursos gratuitos são conveniados às propostas governamentais, por meio de instituições públicas de ensino superior, que são integrantes do Sistema UaB. Todos referem-se à formação de professores/educadores, em parceria com a Secretaria de Educação Continuada, Alfabetização e Diversidade (SECAD) do Ministério da Educação e Cultura (MEC), em nível de pós-graduação lato sensu, sendo aperfeiçoamento (26), extensão (6) e especialização (4) (Figura 1). 
A maioria (27) está alocada em universidades federais e 9 em estaduais. Os cursos públicos em geral priorizam a educação sexual na escola, uma vez que o SECAD/MEC objetiva preparar professores para temas transversais dos currículos de educação básica, que no Brasil contempla a Educação Sexual. Todavia, nenhum programa de curso estava disponível, assim como nenhum deles estava ocorrendo naquele momento.

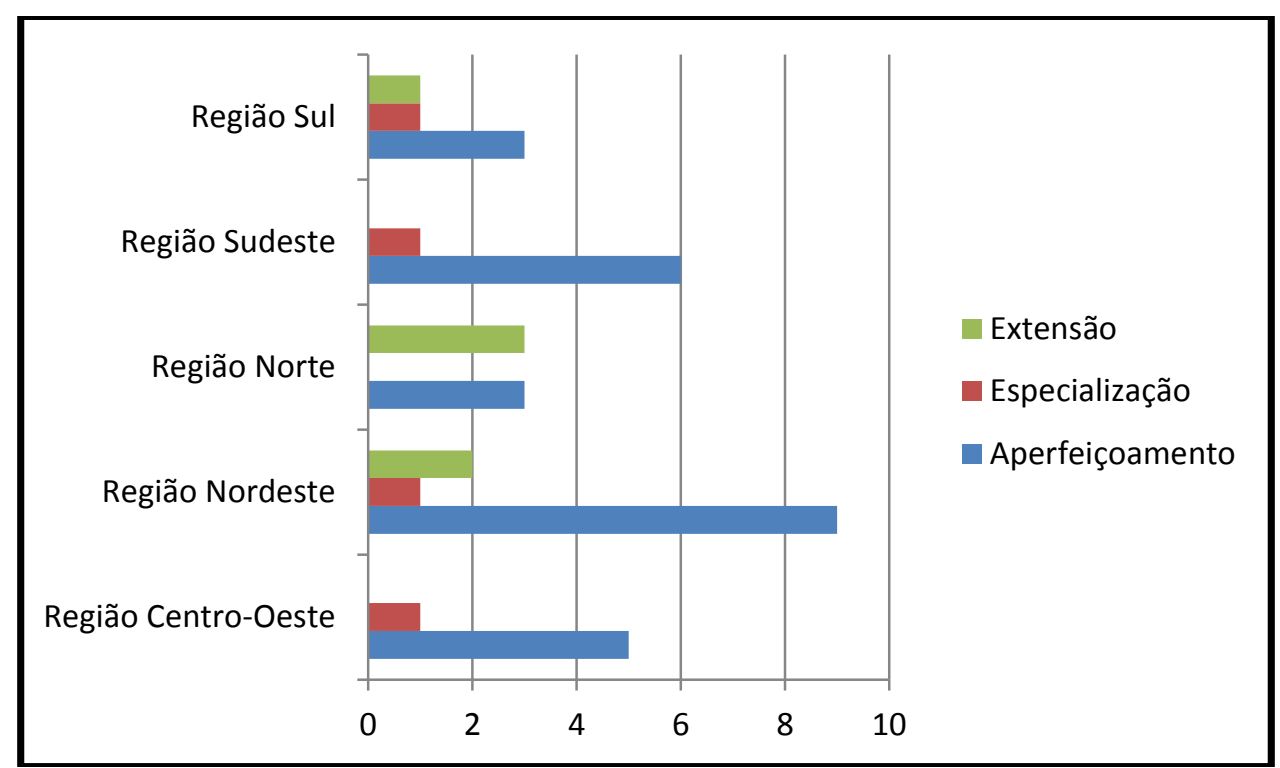

Figura 1. Distribuição dos cursos gratuitos de Instituições públicas

Em relação aos 13 cursos particulares: 7 referem-se a curta duração com até 60 horas; 3 entre 10h/40h a 280h/300h; 2 têm nível de pós-graduação lato sensu com 360h/420h e um, apresenta carga horária inespecífica (Figura 2). 


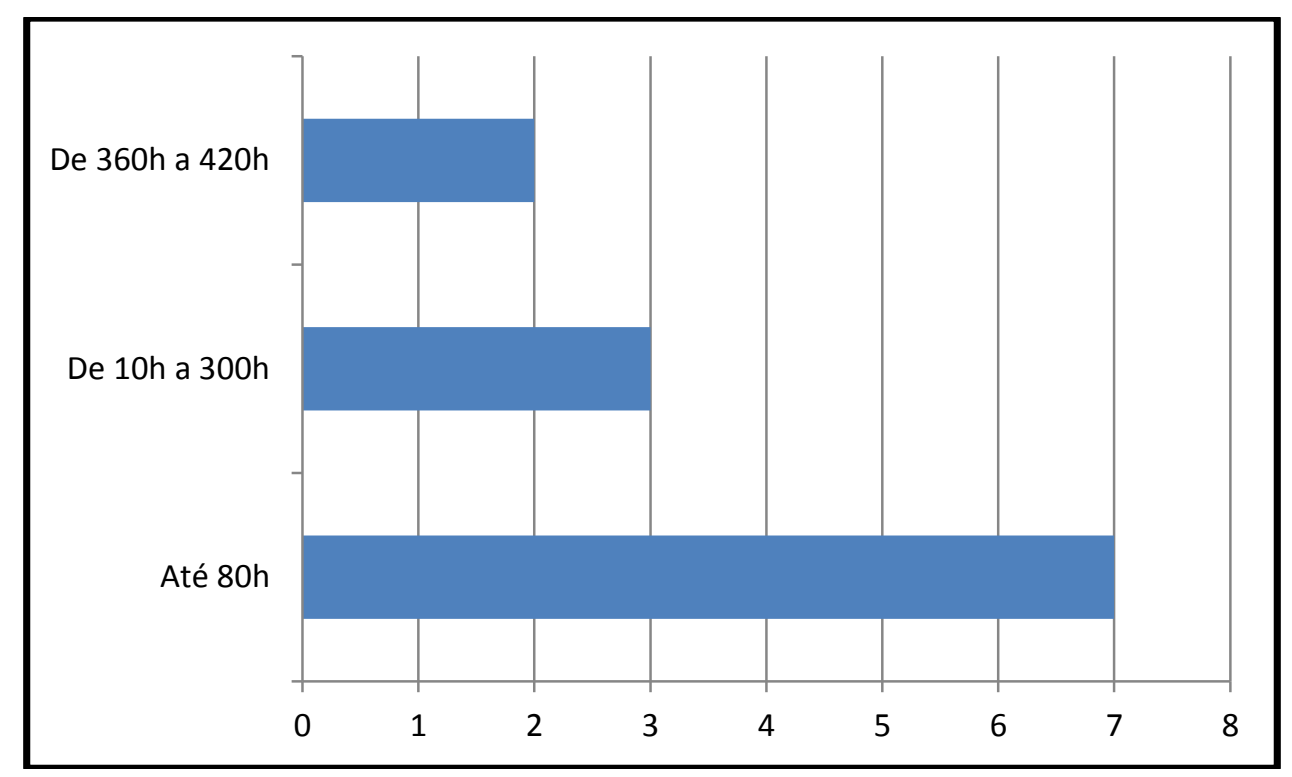

Figura 2. Carga horária dos cursos particulares

Os cursos particulares abordam questões diversas sobre a sexualidade, porém, alguns apresentam grandes listas de assuntos a serem abordados, para uma carga horária pequena, o que sugere não serem aprofundados. Por exemplo: carga horária de $27 \mathrm{~h}$, para abordar uma lista de 43 assuntos, entre eles constam: história da sexualidade, reprodução celular, fecundação, anatomia genital, reprodução, questões biopsicossociais, desvios sexuais, identidade sexual, sexualidades nas fases do desenvolvimento, homossexualidade, sexualidade e deficiência, doenças sexualmente transmissíveis, sexo na internet, erotismo e pornografia, comportamento sexual normal e anormal, entre outros.

\section{Discussão}

Observa-se uma predominância de cursos vinculados a propostas da SECAD, o que se justifica à medida que, no Brasil, cabe ao Estado promover a formação continuada do professor em serviço, porém, foi constatado que nenhum dos cursos estava ocorrendo no momento da coleta, o que inviabilizou a análise do programa do curso, embora esse não fosse o objetivo do estudo.

Por outro lado contrasta com o relato de professores da rede pública apontado no estudo de Maia et al. (2014), em que salientou a relevância da educação sexual em sua formação continuada. 
É preocupante verificar que os cursos particulares em educação sexual apresenta uma carga horária que parece não ser condizente com o programa divulgado, apresentando conteúdos que perpassam aqueles relacionados à sexologia e não propriamente a educação, o que não atende às demandas do professorado brasileiro.

Já nos cursos gratuitos, infere-se que são priorizados conteúdos da educação sexual, uma vez que esse é o objetivo do SECAD, ou seja, sistematizar ações para a formação do professor em serviço, visando atender a legislação em relação aos temas transversais para a educação básica.

Há que se investir mais na formação continuada em educação sexual para os professores, visto que a educação sexual parece ser ineficaz, quando é fundamentada somente em informações, como palestras ministradas por profissionais da saúde, por exemplo (Reis, 2009), prática comum nas escolas brasileiras. Informações, ainda que relevantes e necessárias, não são incorporadas a ações emancipatórias, pois, não são refletidas e agregadas conforme os valores de cada estudante (Figueiró, 2008; Maia, 2010; Nunes \& Silva, 2000).

O professor necessita de formação em sexualidade para atuar de modo pedagógico com temas que os estudantes trazem de casa refletindo valores da família e a interrelação entre escola e família é necessária quando se almeja uma educação sexual emancipatória (Figueiró, 2001; Reis, 2009; Reis \& Maia, 2011). O docente deve estar preparado para exercer o seu papel como educador (PCN, 1997), de modo que não considere a família como obstáculo (Maia et al., 2014), mas sim como parceira na formação do estudante.

A EaD vem ao encontro das necessidades do educador brasileiro, especialmente em relação a suprir as necessidades de formação de tantos professores, uma modalidade defendida como relevante na formação continuada docente (Rodrigues \& Capellini, 2012; Capellini, Rodrigues, Valle, Zanata, Melchiori, Leite, \& Lepre, 2011; Giolo, 2008; Medina \& Dominguéz, 2005; Mostafa, 2009).

A Organização para a Cooperação e Desenvolvimento Econômico - OCDE (2014) divulgou recentemente a pesquisa realizada pela Teaching and Learning International Survey em que a carga horária do professorado brasileiro supera a de outros países, apresentando uma carga horária de 6 horas superior à jornada laboral média de professores de países como Estados Unidos, Chile, Portugal, Inglaterra, Coreia do Sul. Além disso, 60\% deles não têm dedicação exclusiva o que implica em assumir outra escola para lecionar, aumentando ainda mais sua carga semanal de trabalho. Nessa rotina, torna-se difícil para o professor frequentar uma curso de formação continuada presencial 
sendo a EaD uma alternativa viável. Contudo, ele precisa de cursos que lhe garantam uma formação em educação sexual de qualidade.

\section{Considerações Finais}

Os cursos públicos se apresentam em maior número que os particulares, todavia, na época da coleta de dados nenhum deles estava ocorrendo. Por outro lado, os cursos particulares parece não primar pelo aprofundamento dos conteúdos, além de focar na sexualidade relacionada à sexologia e não propriamente à educação.

Neste sentido, seria importante investir na elaboração de cursos no campo da educação que abordem amplamente a temática da sexualidade e objetivem a formação continuada de professores para atuar em práticas educativas nos contextos das escolas.

\section{Referências}

Aretio, GL (1987). Para uma definição de educação à distância. Tecnologia Educacional, Rio de Janeiro, 16, 56-61.

Barros, DMV (2008). Educação a distancia: desafios atuais. In VLMF Capellini (Org.), Práticas em educação especial e inclusiva na área da deficiência mental (pp.135). MEC/FC/SEE: UNESP/FC.

Barros, DMV, \& Reis, VL (2009). A Função Tutorial na Formação Continuada Docente. RIED, 12 (1), 37-62.

Benites, MJO (2006). Educação sexual e formação docente: um estudo a partir de concepções discentes (Dissertação de Mestrado não publicada). Programa de PósGraduação em Educação, Centro de Ciências da Educação, da Universidade Regional de Blumenau - FURB.

Capellini, VLMF, Rodrigues, OMPR, Valle, TGM, Zanata, EM, Melchiori, LE, Leite, LP, \& Lepre, RM (2011). Perfil e Avaliação dos Participantes de um Curso de Formação Continuada em Práticas Educacionais Inclusivas na Modalidade a Distância. Práxis Educativa (Impresso), 6, 79-89.

Figueiró, MND (2008). Iniciação sexual "precoce": Como a educação sexual pode ajudar a imprimir um novo rumo. In MAS Marcondes (Org), Temas transversais e Currículo (pp. 69-103). Brasília: Líber Livro Editora. 
Figueiró, MND (2001). Educação sexual retomando uma proposta, um desafio. Londrina/PR: UEL.

Giolo, J (2008). A educação a distância e a formação de professores. Educação $e$ Sociedade, Campinas, 29 (105), 1211-1234.

Maia, ACB (2010). Conceito amplo de sexualidade no processo de Educação sexual. Psicopedagogia On Line. Retirado de http://www.psicopedagogia.com.br/artigos/artigo.asp?entrID=1303.

Maia, ACB, Reis-Yamauti, VL, Schiavo, RA, Capellini, VLMF, \& Valle, TGM (2014). Opinião de professores sobre a sexualidade e a educação sexual de alunos com deficiência intelectual. Revista Estudos de Psicologia, no prelo.

Medina, AR, \& Dominguéz, CD (2005). La formación del Profesorado ante lós nuevos retos de la interculturalidad. In AR Medina (Org.), Interculturalidad: formación del profesorado y educación. Madrid: Pearson.

Ministério da educação e cultura-MEC (2014). O que é educação a distância?. Retirado de

http://portal.mec.gov.br/index.php?option=com_content\&view=article\&id=1282 3:o-que-e-educacao-a-distancia\&catid=355\&Itemid=230

Mostafa, M (2009). Professores na encruzilhada entre o público e o privado: o curso Gênero e Diversidade na Escola (Dissertação de Mestrado não publicada), Programa de Saúde Coletiva, Instituto de Medicina Social, UERJ.

Nunes, C, \& Silva, E (2000). A Educação Sexual da Criança: Subsídios teóricos e propostas práticas para uma abordagem da sexualidade para além da transversalidade. Campinas, SP: Autores Associados.

Organização para a Cooperação e Desenvolvimento Econômico - OCDE (2014). Carga horária de professor brasileiro em sala de aula supera a de países da OCDE. Retirado de http://www.todospelaeducacao.org.br/educacao-namidia/indice/30673/carga-horaria-de-professor-brasileiro-em-sala-de-aulasupera-a-de-paises-da-ocde/.

Parâmetros Curriculares Nacionais - PCN (1997). Orientação Sexual. Brasília: $\mathrm{MEC} / \mathrm{SEF}$.

Reis, VL (2009). Aspectos Psicossociais da Gravidez na Adolescência: Relatos de Mães Adolescentes (Dissertação de Mestrado), Psicologia do Desenvolvimento e Aprendizagem- Unesp, Faculdade De Ciências, Campus Bauru. 
Reis, VL, \& Maia, ACB (2011). A educação sexual e o conhecimento sobre métodos contraceptivos a partir do relato de mães adolescentes. In EM Zanata, VLMF Capellini, RM Lepre, LF Silva (Orgs.). Formação docente e universalização do ensino: proposições para o desenvolvimento humano (pp.29-35). São Paulo: Cultura Acadêmica.

Rodrigues, LMBC, \& Capellini, VLMF (2012). Formação continuada e educação à distância. Revista Brasileira de Educação Especial, 18 (4), 615-628. 